\title{
Trombosis arterial femoral aguda bilateral en un paciente con COVID-19, con síntomas respiratorios leves. Informe de un caso en el Instituto Nacional de Cardiología
}

\author{
Bilateral femoral artery acute thrombosis in a COVID-19 patient. Case report at the \\ Instituto Nacional de Cardiología
}

Jesús Sánchez-Pacheco* y Guillermo E. Castro Lozano

Departamento de Cirugía Cardiotorácica, Instituto Nacional de Cardiología "Ignacio Chávez", Ciudad de México, México

La pandemia por coronavirus surgida desde el mes de diciembre del 2019 ha sido sin duda alguna la crisis de salud más importante de la última década. Evolucionó con gran celeridad a un carácter de pandemia, lo cual dio origen a múltiples publicaciones en un intento por esclarecer todos los aspectos de esta enfermedad, desde su fisiopatología hasta la búsqueda de un tratamiento específico.

Algunas de las principales complicaciones atribuibles a la infección por SARS-CoV-2 son las relacionadas con el tromboembolismo. El mecanismo fisiopatológico descrito para esta complicación implica la propia infección por SARS-CoV-2, por medio del receptor de la enzima convertidora de angiotensina 2 (ACE 2), que se expresa en varios órganos, entre ellos pulmón, corazón, riñón e intestino. Los receptores ACE 2 también se expresan en las células endoteliales. La presencia del virus dentro de las células endoteliales y una acumulación de factores proinflamatorios, que de manera secundaria podrían producir muerte celular, representan la hipótesis de Varga, et al., cuyos hallazgos sugieren que la infección por SARS-CoV-2 induce la inflamación del endotelio en varios órganos como consecuencia directa de la presencia viral a ese nivel'.
Son de llamar la atención los múltiples informes de infección por SARS-CoV-2, vinculada con trombosis venosa profunda y en ciertos casos con tromboembolismo pulmonar. Sin embargo, las notificaciones de afectación arterial relacionada con la infección son escasas y más limitada aún la vinculación de ésta con la presencia de síntomas respiratorios mínimos, dado que las complicaciones tromboembólicas se acompañan casi siempre de los casos moderados y graves de la infección.

Una exploración física exhaustiva y una adecuada recopilación de datos clínicos pueden llevar no sólo a sospechar el diagnóstico de una complicación tromboembólica, sino también a sugerir el diagnóstico de COVID 19, en pacientes con síntomas respiratorios y cuadro clínico típicos de la enfermedad (fecha de aparición de los primeros síntomas, signos y síntomas respiratorios, fiebre, frecuencia respiratoria, saturación de oxígeno, etc.); sin embargo, en el contexto de un paciente con pocos o nulos síntomas respiratorios, es un grado alto de sospecha sobre la infección posiblemente vinculada con la complicación tromboembólica el que lleva a establecer un diagnóstico preciso en estos pacientes ${ }^{2}$.

\section{Correspondencia:}

*Jesús Sánchez-Pacheco

E-mail: drjesussanchezpacheco@ hotmail.com
Disponible en internet:24-08-2021 DOI: 10.24875/ACM.20000574
Arch Cardiol Mex. 2021;91(Supl):129-133
www.archivoscardiologia.com
es un artículo open access bajo la licencia

Arch Cardiol Mex. 2021;91(Supl):129-133
www.archivoscardiologia.com
es un artículo open access bajo la licencia e es un artículo open access bajo la licencia 


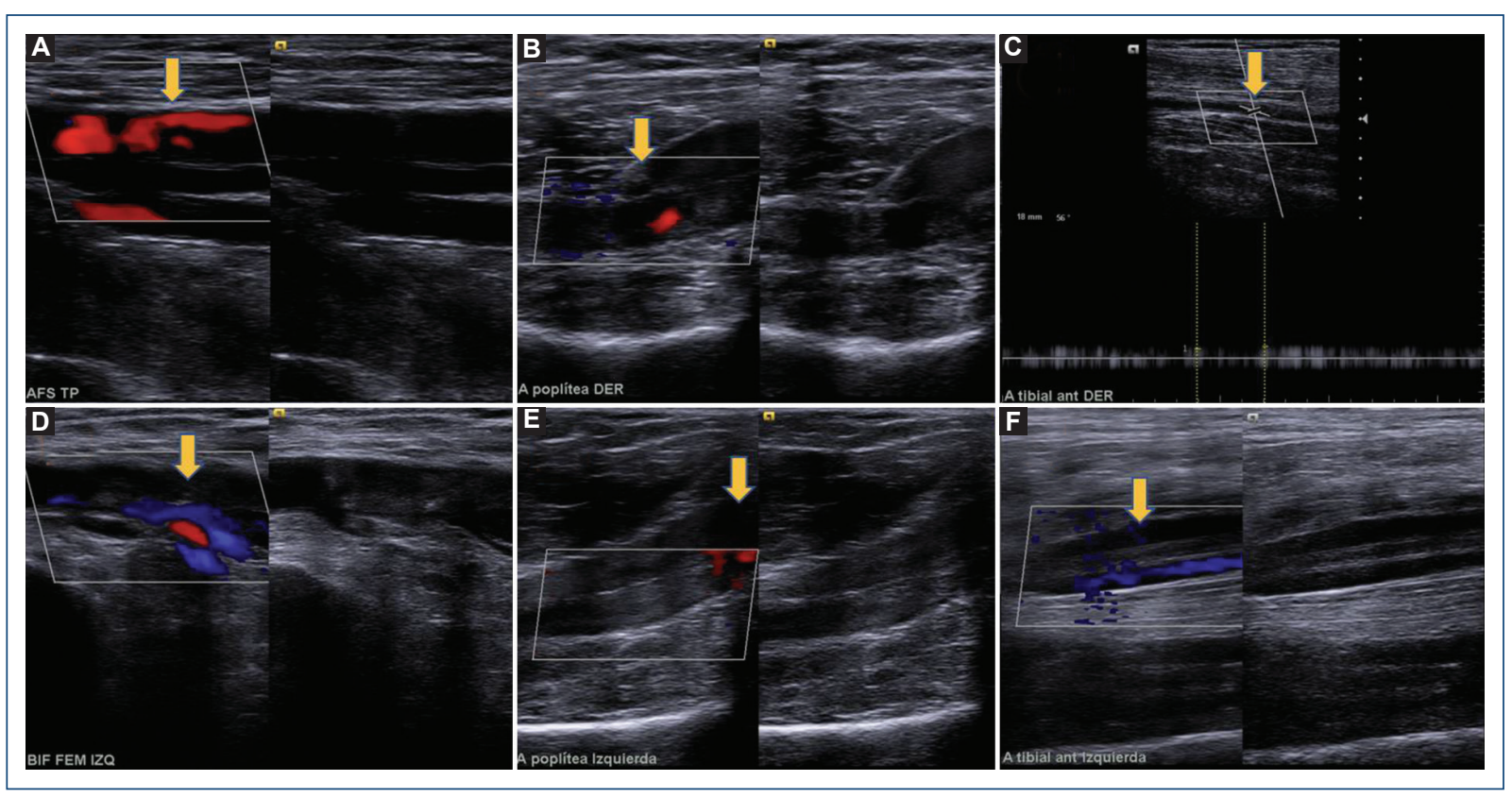

Figura 1. Imágenes de ultrasonido Doppler en las que se demuestran el flujo filiforme desde el nivel de la bifurcación de las arterias femoral común derecha e izquierda $(\mathbf{A}$ y $\mathbf{D})$ y ausencia de flujo en las arterias poplíteas $(\mathbf{B}$ y $\mathbf{E})$ y tibiales anteriores (C y F).

La mayor incidencia de complicaciones tromboembólicas se registra en pacientes críticos, que son admitidos en las unidades de cuidados intensivos. En la revisión de Cheruiyot, et al. se publicó una incidencia de $2.7 \%$ a $8 \%$ de los pacientes admitidos en las unidades de cuidados intensivos. El hallazgo incidental de la enfermedad se observó en dos pacientes, mientras que el resto mostró síntomas de acuerdo con el territorio afectado. La distribución de afectación arterial en las extremidades fue de $39 \%$, sin describir la extensión y compromiso de ésta. La trombosis arterial se acompañó de comorbilidades, como hipertensión arterial, enfermedad cardiovascular, fibrilación auricular, enfermedad renal crónica, entre otras. La mortalidad referida fue de $19.2 \%$ (10 de 52 pacientes) ${ }^{3}$.

\section{Caso clínico}

Se trata de un paciente masculino de 70 años con antecedente de infarto agudo de miocardio anteroseptal en 2003, taquicardia ventricular con ablación no satisfactoria en 2003 y ablación en 2011 exitosa; hipertensión arterial sistémica diagnosticada en 2004, implante de DAl en 2005, enfermedad renal crónica KDIGO G3bA1.

Inició el padecimiento de manera súbita con un cuadro clínico caracterizado por dolor de miembros pélvicos, con intensidad 8/10 desde la región femoral, de predominio en la cara posterior de ambas extremidades; evoluciona con aumento en la intensidad del dolor hasta 10/10 en relación con parestesias, motivo por el que acude al servicio de urgencias para valoración. Al interrogatorio inicial niega síntomas respiratorios, refiere cefalea esporádica y una elevación térmica no cuantificada 15 días antes del padecimiento actual. Al momento de la valoración no muestra síntomas indicativos de infección por SARS-CoV-2 y niega contacto con pacientes positivos o sospechosos de infección por SARS-CoV-2. Es importante mencionar que en la investigación posterior se refiere la presencia de tos nocturna, no productiva, de unos ocho días de evolución.

La exploración física inicial revela una frecuencia cardiaca de $90 \mathrm{lpm}$, frecuencia respiratoria de $20 \mathrm{rpm}$, tensión arterial de 170/70 mmHg y una saturación de oxígeno de $90 \%$ por oximetría de pulso. En su inspección general no se observaron datos de dificultad respiratoria. La exploración física dirigida reveló que los miembros pélvicos se hallaban con pulsos femorales bilaterales presentes y aumentados en intensidad; sin pulsos distales bilaterales desde ese nivel, palidez de las extremidades, hipoestesia, disminución de la temperatura y llenado capilar de $10 \mathrm{~s}$. 


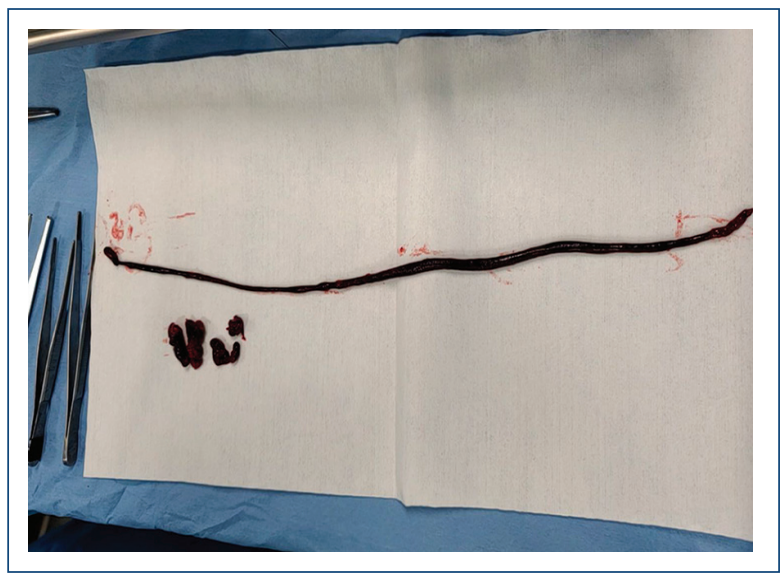

Figura 2. Pieza quirúrgica: trombo arterial femoral izquierdo extendido sobre la mesa de Mayo.

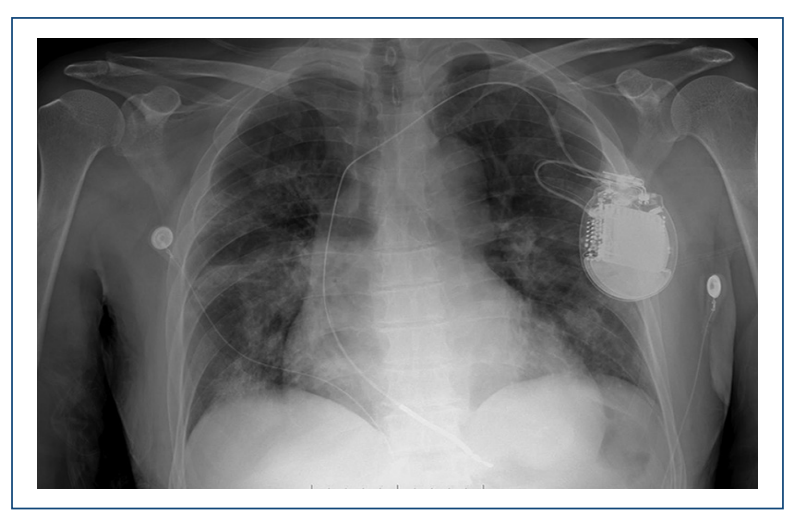

Figura 4. Radiografía de tórax. No se observan alteraciones de tejidos blandos u óseos; se identifican múltiples áreas de consolidación bilateral indicativas de proceso neumónico; DAl localizado en el hemitórax izquierdo.

El electrocardiograma al ingreso registró taquicardia sinusal, $\mathrm{FC} 90 \mathrm{lpm}, \mathrm{aP}+90^{\circ} \mathrm{ms}$, aQRS +30 , onda $\mathrm{P} 100$ $\mathrm{ms}, \pm$ en V1, P-R $160 \mathrm{~ms}$, QRS $80 \mathrm{~ms}$, transición de las precordiales en $\mathrm{V} 1$ con complejos $\mathrm{R} 1$ en $\mathrm{V} 1$ y qR en $\mathrm{V} 6$, con ondas $\mathrm{T}$ invertidas de ramas asimétricas en V2 a V3, y ondas T aplanadas en V1. Extrasístoles con morfología de bloqueo de rama derecha.

Se realizó ecografía Doppler de ambos miembros pélvicos. En la extremidad inferior derecha se reconocieron ecos de bajo nivel intraluminales, que producían flujo filiforme y espectros monofásicos desde la arteria femoral común, femoral superficial en sus tres tercios, poplítea, tibial anterior, posterior y pedia. Se encuentra espectro trifásico a nivel del tercio proximal de la femoral profunda. En la extremidad inferior izquierda se identificaron imágenes ecogénicas intraluminales,

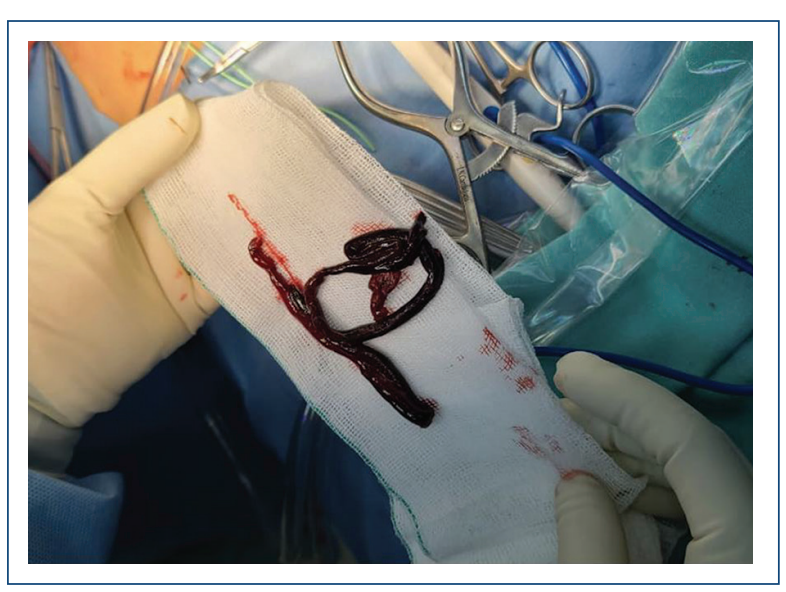

Figura 3. Pieza quirúrgica: trombo arterial femoral derecho.

que se extienden desde la arteria femoral común hasta la arteria pedia, con flujo filiforme hasta el segmento poplíteo y ausencia de flujo en los segmentos distales a ésta. No se identificaron zonas de estenosis (Fig. 1).

Los estudios de laboratorio de ingreso señalaron leucocitos (12.9), linfocitos (2.1), plaquetas $(470,000)$, hemoglobina (14.8), ferritina (472), dímero $D(2.002)$, gasometría arterial con pH (7.45), po2 (63), pco2 (23) y lactato (3.7).

Ante los hallazgos anteriores se decidió practicar una intervención quirúrgica de urgencia, bajo protocolo COVID-19 por el contexto de la pandemia actual.

Ingresó a quirófano con diagnóstico de trombosis arterial femoral aguda bilateral; se realizó un abordaje femoral, con control vascular de la arteria femoral común y sus tres ramas principales, arteriotomía y exploración vascular con catéter de Fogarty 4 y $5 \mathrm{Fr}$, con hallazgo de trombosis arterial extensa de arteria femoral común, femoral superficial, femoral profunda y circunfleja bilaterales. Una vez efectuada la exploración y extraída la pieza quirúrgica (Fig. 2 y 3), se comprobó la presencia de flujo retrógrado y anterógrado, adecuados en ambas extremidades. Se realizó la arteriorrafia con prolene 5-0 mediante técnica de Carrel. El miembro pélvico izquierdo tenía flujo pedio y tibial posterior, con llenado capilar de $3 \mathrm{~s}$ y normotermia. El miembro pélvico derecho con llenado capilar de $6 \mathrm{~s}$, persistencia de la hipotermia local y ausencia de flujo arterial pedio y flujo tibial posterior de intensidad I/II. El paciente egresó de la unidad coronaria con una infusión de heparina no fraccionada de 25,000 UI para $24 \mathrm{~h}$ dosis/respuesta, se realizó una radiografía de tórax en la que se observaron signos indicativos de un proceso neumónico, se confirmó dicho proceso 


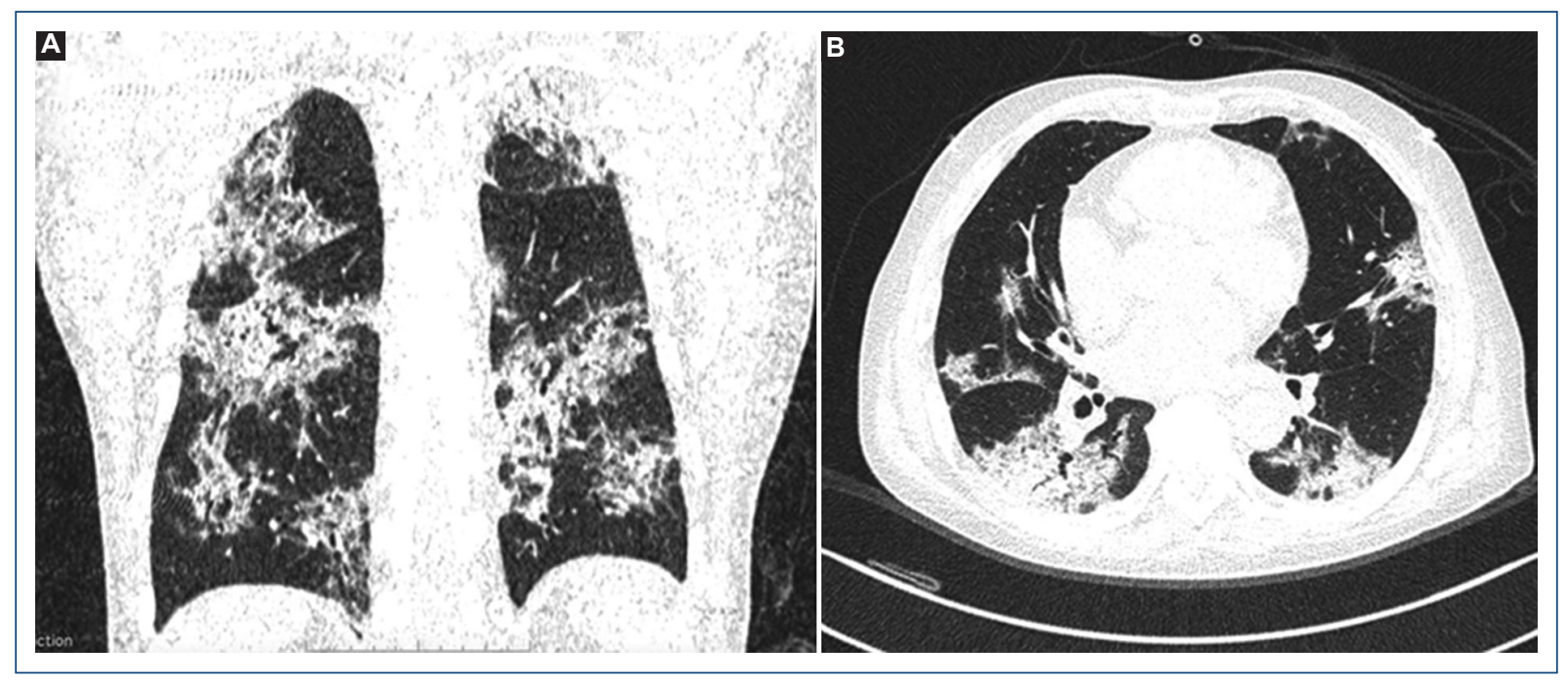

Figura 5. Cortes coronal (A) y transversal (B) de la tomografía de tórax. Se observan múltiples zonas de vidrio despulido de distribución periférica y peribroncovascular con engrosamiento septal interlobulillar, tendencia a la consolidación con broncograma aéreo en los segmentos lingular superior y superiores de ambos lóbulos inferiores. Clasificación CO-RADS 5: anomalías muy indicativas de COVID-19.

por tomografía de tórax en la que se observan múltiples zonas en vidrio despulido de distribución periférica y peribroncovascular, engrosamiento septal interlobulillar con tendencia a la consolidación y broncograma aéreo en segmentos lingular superior y superiores de ambos lóbulos inferiores. Clasificación CO-RADS 5: anomalías altamente indicativas de COVID-19 (Fig. 4 y 5). En la evolución posquirúrgica, el paciente persiste con datos de insuficiencia arterial distal del miembro pélvico derecho. Se corroboró por ultrasonido Doppler la persistencia de trombosis arterial en arterias poplítea y tibial anterior derechas. Se realizó una segunda exploración vascular con abordaje en la fosa poplítea, exploración arterial y trombectomía de las arterias poplítea y tibial anterior derechas. Se confirmaron flujos anterógrado y retrógrado adecuados, arteriorrafia con prolene 5-0 y sutura de Carrel, con mejoría a la exploración dirigida de la extremidad.

Después de la segunda intervención se solicitó una prueba de PCR para detección de COVID-19 con resultado positivo, por lo que se establece tratamiento para COVID-19 en la institución, continuación del aislamiento y vigilancia.

El paciente egresa con evolución satisfactoria posterior a ocho días de aislamiento, tratamiento extrahospitalario con enoxaparina (60 mg cada $12 \mathrm{~h}$ por tres días) y acenocumarol ( $3 \mathrm{mg}$ dosis única, con $2 \mathrm{mg}$ cada 24 h después). Hasta el momento no se han presentado complicaciones posquirúrgicas.

\section{Discusión}

El espectro clínico de los pacientes con COVID-19 varía desde una forma asintomática hasta una enfermedad grave caracterizada por insuficiencia respiratoria, hipoxemia, choque séptico y disfunción multiorgánica, que pueden requerir ventilación mecánica invasiva y estancia en las unidades de cuidados intensivos. El estado protrombótico en los pacientes críticamente enfermos se caracteriza por angiopatía trombótica microvascular y macrovascular. Sin embargo, el estado procoagulante no es exclusivo de pacientes en estado crítico, sino general del paciente infectado por SARS-CoV- $2^{4}$.

La tromboprofilaxis en los pacientes infectados se ha descrito en pacientes críticamente enfermos. Las dosis deben adaptarse, así como el número de aplicaciones diarias en pacientes con alto riesgo trombótico. El uso de estas dosis terapéuticas de anticoagulación está descrito en pacientes con cifras en particular elevadas de dímero $\mathrm{D}$ y otros factores protrombóticos; sin embargo, su uso para otras poblaciones no está bien establecido, por lo que quizá sea necesario indagar más acerca de la posible necesidad de esta medida terapéutica y su viabilidad efectiva en términos del costo². 
Se refiere una incidencia de tromboembolismo arterial o venoso del $35 \%$ en los pacientes internados de unidades de cuidados intensivos y sólo del $2.6 \%$ en los sujetos hospitalizados en pisos generales; no obstante, la trombosis arterial o venosa, como causa principal de los síntomas y la hospitalización, se ha comunicado poco, por lo que el caso presentado parece inusual ${ }^{5}$.

A pesar de lo descrito es necesario subrayar que, en el contexto de la pandemia actual, es necesario considerar la COVID-19 como un posible diagnóstico diferencial, ante los casos de tromboembolismo arterial o venoso, con o sin relación con un cuadro respiratorio.

\section{Conclusión}

El espectro clínico de los pacientes con COVID-19 es amplio y, aunque los síntomas respiratorios parecen ser el común denominador, no debe olvidarse que las presentaciones "no típicas" de la enfermedad son posibles y que, con el inevitable aumento de casos, este tipo de presentaciones será cada vez más frecuente; en consecuencia, los profesionales de la salud deben estar atentos y descartar obligadamente esta enfermedad, cuando la posibilidad de otra causa desencadenante sea mínima, como sospecha principal al padecimiento de los pacientes.

\section{Financiamiento}

Esta investigación no ha recibido ninguna beca específica de agencias de los sectores público o privado.

\section{Conflicto de intereses}

Los autores declaran no tener ningún conflicto de intereses.

\section{Responsabilidades éticas}

Protección de personas y animales. Los autores declaran que para esta investigación no se han realizado experimentos en seres humanos ni en animales.

Confidencialidad de los datos. Los autores declaran que han seguido los protocolos de su centro de trabajo sobre la publicación de datos de pacientes.

Derecho a la privacidad y consentimiento informado. Los autores declaran que en este artículo no aparecen datos de pacientes.

\section{Bibliografía}

1. Varga $Z$, Flammer $A$, Steiger $P$, Haberecker $M$, Andermatt $R$, Zinkernagel $A$, et al. Endothelial cell infection and endotheliitis in COVID-19. The Lancet. 2020;395(10234):1417-1418.

2. Priollet $P$, Yannoutsos $A$, Mourad J. Ten key points that vascular doctors learned very quickly about COVID-19. JMV-Journal de Médecine Vasculaire. 2020;45(3):105-106.

3. Cheruiyot I, Kipkorir V, Ngure B, Misiani M, Munguti J, Ogeng'o J. Arterial Thrombosis in coronavirus disease 2019 patients: a rapid systematic review. Annals of Vascular Surgery. 2020;70:273-281.

4. Di Gennaro F, Pizzol D, Marotta C, Antunes M, Racalbuto V, Veronese N, et al. Coronavirus diseases (COVID-19) current status and future perspectives: a narrative review. International Journal of Environmental Research and Public Health. 2020;17(8):2690.

5. Piazza G, Campia U, Hurwitz S, Snyder J, Rizzo S, Pfeferman M, et al. Registry of arterial and venous thromboembolic complications in patients with COVID-19. Journal of the American College of Cardiology. 2020;76(18):2060-2072. 